\title{
Factors Constraining Extension Workers Effectiveness in Improving Horticultural Production: A Case Study from West Timor Indonesia
}

\author{
Rafael Leta \\ Agricultural Faculty of Nusa Cendana University, Kupang, Indonesia \\ Roy Murray-Prior and Fay Rola-Rubzen \\ Muresk Institute, Curtin University of Technology, Northam, WA, Australia
}

Key Words: Role, Extension Worker, Horticulture, Agribusiness

\begin{abstract}
The Indonesian government and the government of Nusa Tenggara Timur recognise that horticulture is economically important and is expected to become the leading agribusiness sector to overcome poverty for farmers. Hence, in the last 20 years, the government of Nusa Tenggara Timur through various agribusiness projects has encouraged the planting of more than 18,490 hectares of vegetables and 82,010 hectares of fruit. The major producing areas of both are in the Kupang district and in the Timor Tengah Selatan. However, productivity is low. If production can be increased, on-farm income may also increase, but this is dependent upon Agricultural Extension Workers performing their roles more effectively. This study investigates the constraints that impede the ability of Agricultural Extension Workers to effectively perform their roles. The results suggest that while Agricultural Extension Workers are not performing their roles effectively there are a number of reasons for this, many of them beyond the control of Agricultural Extension Workers. While the Nusa Tenggara Timur province is supposedly following the Training and Visits model Agricultural Extension Workers receive very little training. Other major constraints identified include the constant restructuring of the Agricultural Department, poor remuneration, oppressive authority, inadequate infrastructure, unclear job direction, geographical condition, and bureaucracy. Unless these constraints are addressed, the system will remain unable to deliver the information and skills necessary for farmers to overcome poverty.
\end{abstract}

\section{INTRODUCTION}

Most farmers in West Timor, especially in Kupang and Timor Tengah Selatan (TTS) cultivate oranges, watermelons, chillies, cabbages and other vegetables. Oranges, specifically the variety "jeruk keprok", have become a specialty crop in West Timor. In 1997 , oranges and watermelons provided $23 \%$ of total production by weight of the six main fruit crops, while cabbages, chillies and carrots contributed $36 \%$ to the total of the sixteen major vegetable crops (Food and Horticultural Crops Division NTT 2000).

However, most farmers in West Timor are still living in poverty with the average per capita income approaching just Rp1,200,000 or AUD550 per year (Statistics of NTT 2004). While the local government believes that horticultural crops will become one of the leading economic sectors, productivity remains low. To increase production, the government has directed Agricultural Extension Workers (AEWs) to redirect their 
farmer-based programs towards improving horticultural production. As production increases, farm incomes are expected to improve. However, despite the various mandates little improvement has occurred. This paper identifies those constraints that adversely impact upon the ability of AEWs in West Timor to more adequately perform their duties.

\section{THEORETICAL BACKGROUND}

Van den Ban and Hawkins (1996) suggested that government should have appropriate policies and take responsibility for and be committed to agricultural extension institutions. Sundaraswamy and Perumal (1992) also indicate the organisation's climate and commitment can lead to extension workers satisfaction and that they have to be trained regularly.

Kumuk (1992) mentioned that field workers who visit farmers frequently require regular training. Axinn and Thorat (1972 as cited by Leta, 2002) argue training for extension workers is the vitally important aspect of extension service. To obtain good performance Williams and Bembridge (1990) suggest that AEWs should be trained every two weeks to support their roles.

However, Rao and Rao (1998) and Asiabaka and Bamisile (1991) mentioned that field workers are the poorest paid government officials. In most cases, AEWs do not earn sufficient income from their jobs to sustain themselves and their families. To perform their jobs, Blackenburg (1982) insists that AEWs should be adequately resourced. Both Van den Ban and Hawkins (1996) and Kassa (1999) have suggested that extension workers often do not have sufficient transport available for them to reach farmers. This is compounded by the fact that in remote places, field workers cannot work effectively because of bad geographical conditions (Kalshoven 1978).

Rao and Rao (1998) argue AEWs should have authority to take decisions on the merits of the problems, because job authority may affect AEWs' performance (Sundaraswamy and Perumal, 1991). Librero and Broonrung (1978 as cited by Leta, 2002) suggested that guidance and direction of extension requires careful study because extension services involve a variety of extension institutions. An additional complication is that agricultural institutions in Indonesia are very complicated Padmanegara (1985).

\section{METHOD}

The study investigated the roles of Agricultural extension workers in horticultural agribusiness in Nusa Tenggara Timur (NTT) Indonesia. Face-to-face interviews were conducted between September 2000 and February 2001 with 223 farmers, 46 agricultural extension workers and 32 government officers from the Kupang and TTS districts. The questions for evaluating the extension activities included inputs or sources of planning, activities, participation, and reaction were designed with reference to Bennet's hierarchy (Bennett 1979). There was some overlap in questions in the survey instruments for the three groups particularly with respect to the roles of AEWs and the quality of their services. The latter questions were based on the SERVQUAL model (Lovelock 1991). Constraints that impede the ability of AEWs to adequately perform their roles and factors affecting their job satisfaction were also investigated. 


\section{RESULTS AND DISCUSSIONS}

\section{Respondent demographics}

More than half (57\%) the AEW's were male. The average age of the AEW's was 38 years (range 28 and 50 years). Although the average length of time AEWs had been working with extension services was 12.3 years (range shortest time of 4 years and longest 24 years), most AEWs had worked in their district for only 3 years (range less than 1 year to 4 years). Most AWE's (69\%) had only Senior High School (69\%) qualification (Leta 2002).

\section{Factors Constraining AEWs Effectiveness}

Based on the factors ranked by AEWs, the most common constraints were respectively; 1) the constant restructuring of the Agricultural Department; 2) inadequate salary or rewards, 3) act without authority, 4) inadequate training; 5) lack of resources or facilities; 6) poor direction; 7) geographic conditions; and 8) bureaucratic management style (Table 1). As shown in Fig. 2 these factors interact with each other to lead to poor performance.

1. The restructuring of Agricultural Institutions. On four occasions over the last twenty-five years (1980, 1991, 1996 and 2001), the Agriculture Department in Indonesia has been restructured. Economic and political instability has had a negative impact on agricultural policy including a change in the position of AEWs within the Agriculture Department structure. Since the implementation of regional autonomy (July 1, 2001), the provincial Department of Agricultural and BIPP at district level have been restructured. The implementation of this policy has put AEWs in a very difficult situation within their administration system. The chain of command has been moved from the Agriculture Department to the Regional Secretary at provincial and district level (Agricultural Department of Indonesia 2001). This seems to conflict with suggestions made by Van den Ban and Hawkins (1996) that government should be committed and responsible for agricultural extension institutions.

2. Low salary. The majority of AEWs (98\%) were very dissatisfied with the salary provided by the government. Government and others will often blame AEWs if a program is not successful. However, if the program is successful, while AEWs are never rewarded government officers are promoted.

3. Act without authority. Many AEWs suggested that they undertook their roles/tasks almost without authority, especially when making decisions. As can be seen in Fig. 2, when AEWs met farmers' problems, they had to inform the BPP coordinator. While waiting for the government to solve farmers' problems, in theory, AEW's should do nothing. As a consequence, AEWs expressed their dissatisfaction with the authority given by the government. AEWs attitude are supported by Rao and Rao (1988) who suggest that AEWs should have authority to take decisions on the merits of the problems because job authority may affect AEWs's performance (Sundaraswamy and Perumal, 1991). 
4. Chance for training. Most AEWs were dissatisfied because in 2000 most had not attended any formal training course, while $42 \%$ have never attended any course. Most AEWs expressed their dissatisfaction because the government only invites AEWs who work with specific projects to attend training/course.

On the subject of training, most AEWs also expressed dissatisfaction because the government provides training based on the specific project rather than local needs. It seems that there is a positive relationship between the number of AEWs attending training courses in Participatory Rural Appraisal (37\%) and the number of AEWs who have identified farmers' problems (52\%). Based on evidence, it can be concluded that one of the reasons AEWs do not visit farmers is that they have not been trained regularly. To obtain good performance from AEWs in running their role, they have to be trained regularly (Sundaraswamy and Perumal 1992).

5. Lack of resources or facilities. AEWs concede that the lack of resources to support their activities in the villages created much dissatisfaction. Each BPP that was used as a base for AEWs has its own office with one meeting room, one typewriter and one motorbike. However, these facilities are mostly used by the BPP coordinator. These facilities, of course, are not enough for five to 17 AEWs who work with a BPP. This results seems similar with Blackenburg (1982), Van den Ban and Hawkins (1996) and Kassa (1999) who have suggested that extension workers often do not have sufficient transport available to reach farmers.

6. Unclear directions. AEWs were also dissatisfied with the directions often provided by the government to fulfil their tasks. At the village level, it is often difficult to follow the government directions. At the village level, high-level officials supervise the program and provide directions based on their interpretation of priorities which are often inconsistent with policy. To support this finding, farmers, AEWs and local government officers suggest that the government should seek to improve coordination at the village level.

7. Geographical conditions. AEWs also felt geographical conditions made it very hard for AEWs to reach farmers in a village. The settlement area of farmers in a village spreads in some groups up to $20 \mathrm{~km}$ within the village and $30 \mathrm{~km}$ or more between villages. Beside that, there may be no permanent roads and some villages can only be reached by foot. This finding is consistent with findings by Kalshoven (1978) that in remote places, AEWs can not work effectively because of bad geographical conditions.

AEWs are reluctant to live in the village. As found by Leta (2002), only three AEWs actually live in the village where they serve. There are various arguments for having AEWs live in the villages. They will be in a better position to meet local people and understand their social system (IRRI, 1990). This can lead to improved communication. However, AEWs also need to be able to meet and communicate with their peers, contact farmers and researchers. This is generally not possible while living in a village, which may be isolated and stagnating. The solution would appear to be not so much where the AEWs live, but in supplying the transport and training programs so that they can more easily contact farmers with appropriate information.

8. Bureaucratic management processes. With respect to the bureaucracy and its impact on AEWs roles and tasks, most AEWs were dissatisfied with the bureaucratic system 
within government. This is supported by Padmanegara (1985) who observed that the agricultural institutions in Indonesia were very complicated.

When AEWs found a problem which threatened farmers' crops (e.g. disease), AEWs then reported the incident to a higher level official such as the coordinator of BPP. The BPP coordinator then reported it to the BIPP and to the relevant division and so on in some cases up to the governor. Hence, despite farmers and AEWs facing problems which need to be overcome quickly, they have to wait for a decision from a high-level official whether or not or how the problem should be overcome.

\section{CONCLUDING REMARKS}

AEWs and the extension system in NTT appear to be performing poorly, but the lack of success is not due only to AEW performance, but also to system failure. While it can be argued that the top-down $\mathrm{T} \& \mathrm{~V}$ model may not be the most appropriate, its implementation in NTT is not a fair test. Many of its key elements, which would be required for any successful extension operation, do not appear to be in place. There is a lack of relevant local research, resources, planning, marketing outlet information, facilities, and control; and AEWs are not receiving sufficient training in appropriate technology. The bureaucratic processes and bad geographical conditions also impede AEWs, who do not appear to be making sufficient visits to farmers or delivering services on time.

There is no point in changing the model without addressing these issues. However, its important that the government should enhance AEWs' ability to improve the horticultural productivity by refining AEWs' position on agriculture, increase the rewards or salary, provide authority to solve the problems, provide sufficient training, provide sufficient facilities, clear direction, and simplifying management.

\section{References}

Agricultural Statistic of NTT 2002. Agricultural Production of NTT, Kupang. Indonesia. Agricultural Department of Indonesia 2001. Autonomy Administration for Extension Workers. Agricultural Department of Indonesia, Jakarta.

Ashraf, A. 1993. Poverty alleviation and sustainable development. Journal of Rural Development and Administration, 25:71-75.

Asiabaka, C. C. and Bamisile, A. I. 1991. An Assessment of The Performance of Agricultural Extension Agents: A Case Study of Lagos State Agricultural Development project. Journal of Rural Development, 10:705- 713.

Blackenburg, P. Von 1982. The Training and Visit Agricultural Extension: A Review of First Experiences. Quarterly Journal of International Agriculture, 21: 6-25.

Food and Horticultural Crops Division of NTT 2000. The statistics of Food and Horticultural Production. Food and Horticultural Crops Division, East Nusa Tenggara Province. Kupang, Indonesia.

International Rice Research Institute 1990. Performance Objective Manual, Training and Transfer Technology Course, Los Banos, Laguna, Philippines

Kumuk, T. 1992. An alternative solution instead of Village Extension Worker within the T \& V system, Ege Universitesi Ziraat Fakultesi Dergisi, 29:175-180. 
Kassa, B. 1999. Constraints to effective extension work in Ethiopia : the insider' view, Alemaya University of Agriculture Dire Dava, Alemaya, Ethiopia. Rural and Tropag.

Kalshoven, G. 1978. Agricultural Extension in Surinam: Communication and the role of extension workers at the periphery of their agency, Agricultural Adminsitration, UK. 5:165-181.

Leta, L.R. 2002. Role of Agricultural Extension Workers in Horticultural Agribusiness in East Nusa tenggara Province Indonesia. Masters Thesis in Rural Management, Muresk Institute of Agriculture, Curtin University of Technology, Northam WA, Australia.

Padmanegara, S. 1985. The Joint Formulation of Extension Message by Research and Extension Staff in Indonesia, World Bank, Washington D.C., USA.

Rao- A B S and Rao B S. 1998. Job satisfaction of village extension officers working in T \& V system of Srikakulam District, Andhra Pradesh. Journal of Research ANGRAU, Department of Extension. College of Agriculture, Hyderabad, India, 26:49-53.

Statistic of NTT 2004. NTT In Figure, Kupang, 2004.

Sundaraswamy, B. and Perumal, G. 1992. Variables influencing the job performance of Extension Assistant Agricultural Officers. J. Agric. Sci. 5: 249-254.

Van den Ban, A.W. and Hawkins, H.S. 1996. Agricultural Extension. $2^{\text {nd }}$ edn. Blackwell Science Pty Ltd, Victoria.

Williams J.L.H. and Bembridge, T.J. 1990. Training and visit extension: a model for Southern Africa. South African Journal of Agricultural Extension. 23-30. 
Tables

Table 1. AEWs' perception on the factors that impede their ability to fulfil their role

\begin{tabular}{|c|c|c|c|c|c|c|c|}
\hline Constraints factors & $\begin{array}{c}\text { Strongly } \\
\text { dissatisfied }\end{array}$ & Dissatisfied & Neutral & Satisfied & $\begin{array}{l}\text { Strongly } \\
\text { satisfied }\end{array}$ & Mean & SD \\
\hline $\begin{array}{l}\text { AEWs on agricultural } \\
\text { structure }\end{array}$ & $65 \%$ & $35 \%$ & $0 \%$ & $0 \%$ & $0 \%$ & 1.5 & 0.71 \\
\hline Salary & $24 \%$ & $74 \%$ & $2 \%$ & $0 \%$ & $0 \%$ & 2.0 & 1.00 \\
\hline Authority & $15 \%$ & $46 \%$ & $39 \%$ & $0 \%$ & $0 \%$ & 2.0 & 1.00 \\
\hline Training frequency & $53 \%$ & $39 \%$ & $4 \%$ & $4 \%$ & $0 \%$ & 2.5 & 1.29 \\
\hline Facility & $26 \%$ & $52 \%$ & $13 \%$ & $9 \%$ & $0 \%$ & 2.5 & 1.29 \\
\hline Job direction & $17 \%$ & $57 \%$ & $20 \%$ & $6 \%$ & $0 \%$ & 2.5 & 1.29 \\
\hline Geographical conditions & $22 \%$ & $41 \%$ & $24 \%$ & $13 \%$ & $0 \%$ & 2.5 & 1.29 \\
\hline Bureaucracy & $11 \%$ & $46 \%$ & $30 \%$ & $13 \%$ & $0 \%$ & 2.5 & 1.29 \\
\hline
\end{tabular}

Source: Leta (2002) 


\section{Figures}

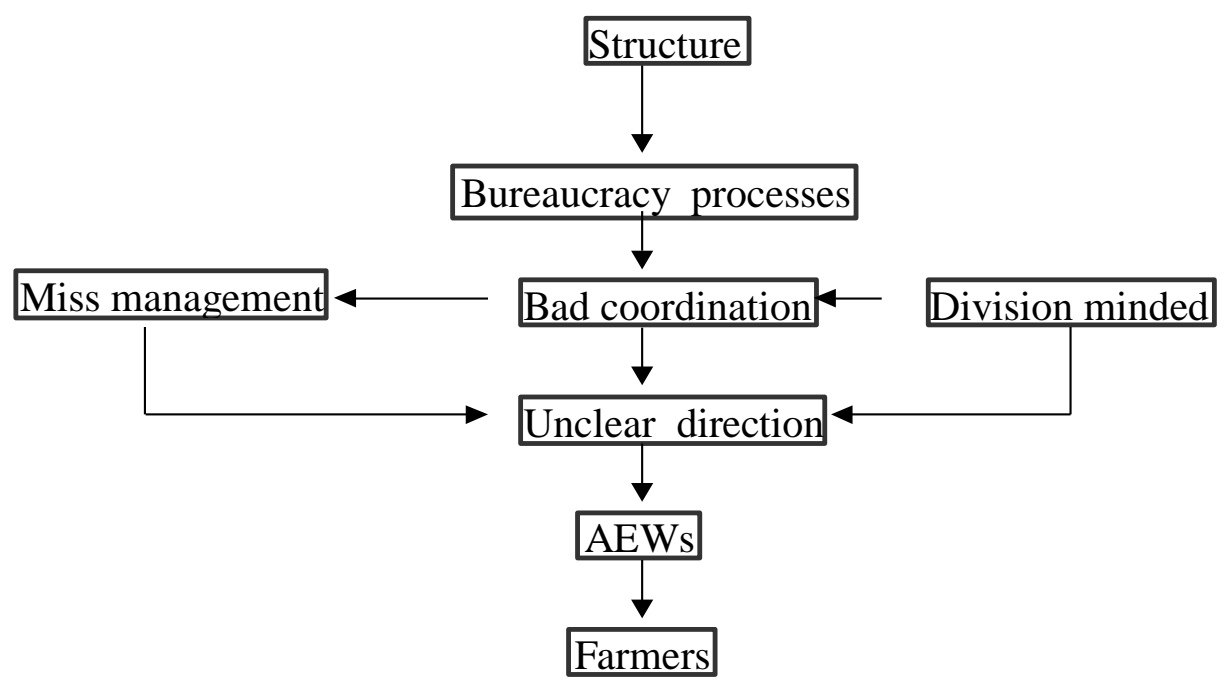

Source: Leta, 2002

Fig. 1: Model of factors constraining extension effectiveness

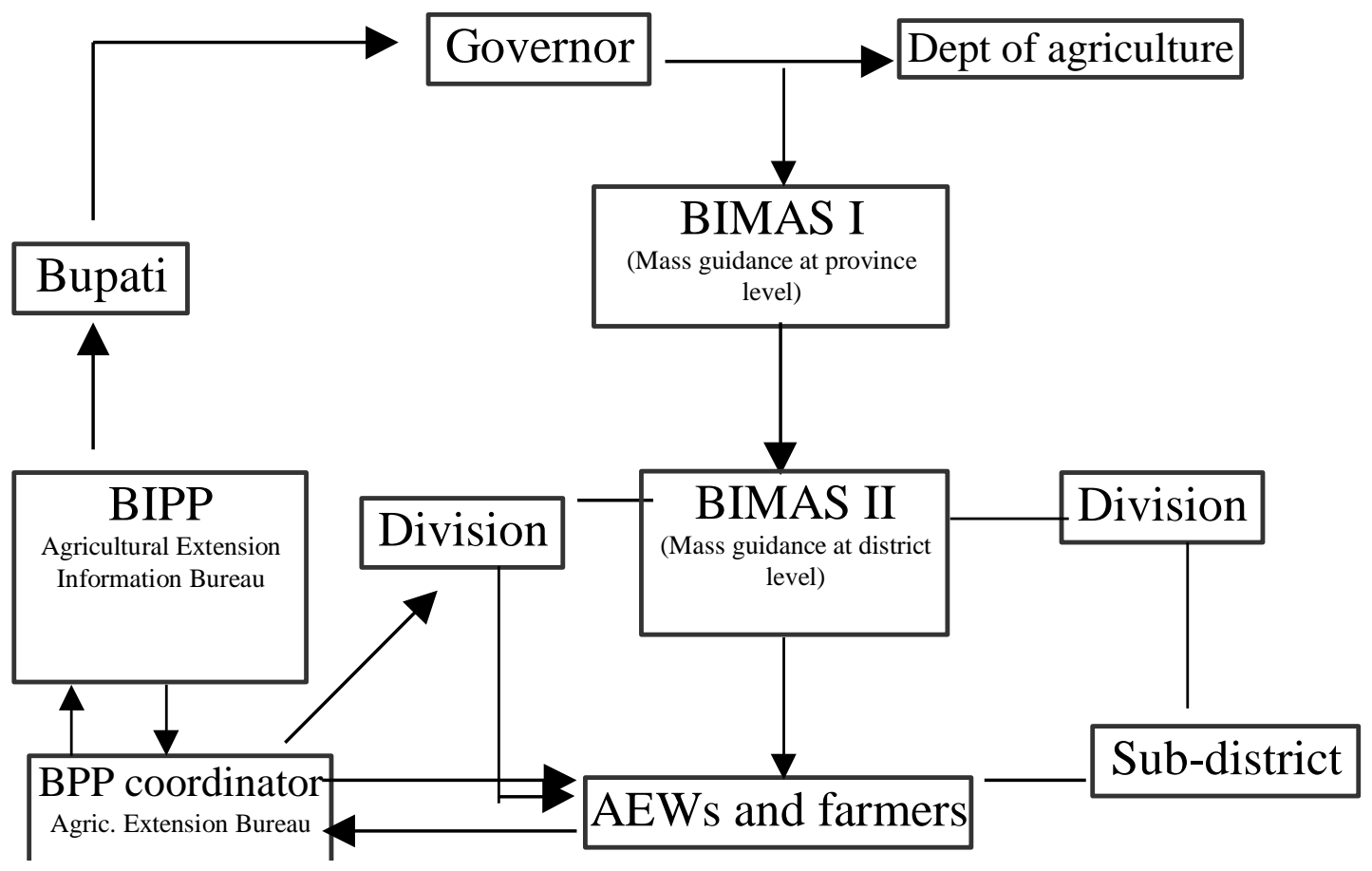

Source: Leta, 2002.

Fig. 2. Model of extension bureaucracy 